\title{
Sequential multiplex PCR for determining capsular serotypes of pneumococci recovered from Brazilian children
}

Correspondence
Bernard Beall
BBeall@cdc.gov

Received 16 April 2007

Accepted 24 May 2007

\author{
Cícero A. Dias, ${ }^{1,2}$ Lúcia Martins Teixeira, ${ }^{2}$ Maria da Glória Carvalho ${ }^{3}$ \\ and Bernard Beall ${ }^{3}$
}

\author{
${ }^{1}$ Fundação Faculdade Federal de Ciências Médicas de Porto Alegre, and Hospital Mãe de Deus, \\ Porto Alegre, Rio Grande do Sul, Brazil \\ ${ }^{2}$ Instituto de Microbiologia, Universidade Federal do Rio de Janeiro, Rio de Janeiro 21941-590, \\ Brazil \\ ${ }^{3}$ Respiratory Diseases Branch, Division of Bacterial Diseases, Centers for Disease Control and \\ Prevention, Atlanta, GA 30333, USA
}

Capsular serotype surveillance of clinical isolates of Streptococcus pneumoniae is essential for evaluation of the potential impact of introducing multivalent capsular serotype-based vaccines in Latin America. Here, a previously described sequential multiplex PCR method was revised for optimal targeting of prevalent serotypes in Latin America. The revised protocol successfully serotyped 139/147 pneumococci (94.6\%) from Brazilian children, demonstrating a labour-efficient, accurate method requiring only conventional PCR capability.

\section{INTRODUCTION}

Streptococcus pneumoniae causes up to 1 million deaths per year among children less than 5 years of age, mostly in developing countries (Hausdorff et al., 2000; Garcia et al., 2006). The antiphagocytic polysaccharide capsule of $S$. pneumoniae is an essential virulence factor, with 91 known types distributed among this normally commensal inhabitant of the nasopharynx (Park et al., 2007). About 15 serotypes appear to cause the majority of invasive infections (Hausdorff et al., 2000; Robinson et al., 2001; Whitney et al., 2003). In Latin America, 13 capsular types account for $>85 \%$ of invasive isolates (Di Fabio et al., 2001; Garcia et al., 2006; Laval et al., 2006).

The introduction of the seven-valent pneumococcal conjugate vaccine (PCV7) resulted in a dramatic decline in invasive disease caused by $S$. pneumoniae in children and a significant decline in the non-vaccinated population due to a pronounced herd effect (Whitney et al., 2003, 2006; Ray et al., 2006). Serotype surveillance will continue to be necessary in vaccinated and non-vaccinated populations for evaluation of the impact and suitability of current multivalent vaccines (Whitney et al., 2003; Ghaffar et al., 2004; Kyaw et al., 2006). Studies of serotype distribution rely on conventional serotyping (the Quellung reaction) for direct determination of serotypes of $S$. pneumoniae. The expense and intrinsic technical difficulties of conventional serotyping limit its use to a few highly specialized

Abbreviation: CDC, Centers for Disease Control and Prevention. laboratories. Multiplex PCR-based methods that specifically identify capsular serotype-specific sequences offer a simple and economical approach for the surveillance of pneumococcal disease (Brito et al., 2003; Pai et al., 2006). Sequential multiplex PCR was recently developed for deducing 29 serotypes or serogroups (Pai et al., 2006), providing the capability to perform surveillance of serotypes causing the majority of disease for laboratories with basic DNA amplification and electrophoresis equipment.

The purpose of our study was to test a reformulation of the current sequential multiplex PCR procedure (Pai et al., 2006), modified on the basis of past surveillance, to identify the most frequent serotypes of $S$. pneumoniae isolated in Latin America (Di Fabio et al., 2001; Garcia et al., 2006; Laval et al., 2006). In the accompanying study (Morais et al., 2007), we present the same strategy based on past serotype surveillance in Mozambique. It is important to demonstrate the flexibility of the general method by altering combinations of serotype specificities and to demonstrate that each serotype-specific primer pair is specific for a given serotype, regardless of strain diversity within different countries.

\section{METHODS}

Bacterial strains and culture conditions. A collection of $147 \mathrm{~S}$. pneumoniae isolates was obtained from children less than 5 years old living in the city of Porto Alegre, Brazil. Most of the isolates (115/147; $78.2 \%$ ) were recovered from normally sterile fluids, comprising blood (74 isolates), cerebrospinal fluid (19 isolates) and pleural fluid (22 isolates). Twenty-seven different serotypes were represented in the 
collection: serotypes 14 (45 isolates), 6B (23 isolates), 19F (nine isolates), 18C (eight isolates), 1 (seven isolates), 3 (seven isolates), 9V (six isolates), 23F (six isolates) and 5 (five isolates), followed by serotypes $6 \mathrm{~A}, 19 \mathrm{~F}, 23 \mathrm{~B}$ (four isolates each), 11A (three isolates), 8 and 16F (two isolates each), and serotypes 7C, 7F, 9N, 10A, 13, 15B, 18A, 24B, 28A, 29,31 and 34 (one isolate each). Bacteria were cultured on trypticase soy agar with $5 \%$ sheep blood BBL (BD) in $5 \% \mathrm{CO}_{2}$ at $37{ }^{\circ} \mathrm{C}$.

Optochin-susceptibility test. Optochin-susceptibility testing was performed as described previously (Arbique et al., 2004) to identify $\alpha$ haemolytic colonies as S. pneumoniae.

Bile solubility test. The tube bile solubility test was performed as described previously (Arbique et al., 2004) to identify $\alpha$-haemolytic colonies as $S$. pneumoniae.

Quellung serotype reaction. All serotype results were confirmed with sera prepared at the Centers for Disease Control and Prevention (CDC), using latex agglutination followed by the Quellung reaction.

DNA extraction and multiplex PCRs. DNA extraction and multiplex PCRs were performed as described previously (Pai et al., 2006) with modifications: serotype 14 primers were redesigned to avoid the occurrence of cross-reactivity among isolates of serotypes $15 \mathrm{~B}$ and 15C. The new type 14 primers were 14-F2 (5'-GAAATGTTACTTGGCGCAGGTGTCAGAATT-3') and 14-R2 (5'-GCCAATACTTCTTAGTCTCTCAGATGAAT-3'), which yielded an amplification product of $189 \mathrm{bp}$ from serotype 14 pneumococci. Type $9 \mathrm{~N}$ specificity was added to the typing scheme, as $9 \mathrm{~N}$ is a common serotype among clinical pneumococcal isolates of this region. Primers targeting 9N (9N/L-F: 5'-GAACTGAATAAGTCAGATTTAATCAGC3'; and 9N/L-R: 5'-ACCAAGATCTGACGGGCTAATCAAT-3') also detect the rarely occurring 9L serotype, yielding a product of $516 \mathrm{bp}$. The primer concentrations for serotypes 14 and $9 \mathrm{~N} / \mathrm{L}$ were 1.0 and $0.5 \mu \mathrm{M}$, respectively, and in all reactions of the Latin America scheme, a concentration of $3.5 \mathrm{mM} \mathrm{MgCl}_{2}$ was used.

Isolates were typed using the current scheme used in the USA (Pai et al., 2006) and an alternative scheme targeting the most prevalent serotypes in Latin America, in which the 13 most prevalent serotypes in Latin America (Di Fabio et al., 2001; Garcia et al., 2006; Laval et al., 2006) were included in the first three reactions. Primers for serotypes
5 and 9N/L were also included for a total of 30 serotypes distributed among six multiplex PCRs (Table 1).

\section{RESULTS AND DISCUSSION}

The six multiplex PCRs included the corresponding serotype controls from the CDC collection and the internal positive control cpsA (Fig. 1). PCR-deduced results from both schemes were concordant with conventional serotyping. Using the previously described scheme (Pai et al., 2006), serotypes or serogroups were accurately predicted for $133 / 147(90.5 \%)$ of the isolates (Table 1). The remaining 14 isolates were of serotypes not included in the scheme, including types 5 (five isolates), 23B (four isolates), $9 \mathrm{~N}$ (one isolate), 13 (one isolate), 24B (one isolate), 28A (one isolate) and 29 (one isolate).

Using the first three reactions of the Latin America scheme, serotypes were accurately deduced for $131 / 147$ (89.1\%) of the isolates (Table 1). The remaining three reactions were used to deduce correctly the serotypes or serogroups from eight additional isolates, to give a final total of 139 (94.6\%) of the 147 isolates. These results demonstrate the adaptability of this method for grouping alternative combinations of serotype-specific primer sets. In order to assure the specificity of PCR 3 for serotype 9N/9L, all six isolates of serotype $9 \mathrm{~V}$ were subjected to PCR 3 without yielding an amplification product.

Eight isolates of serotypes $23 \mathrm{~B}$ (four isolates) and 13, 24B, $28 \mathrm{~A}$ and 29 (one isolate each) were not amplified, as these serotype specificities were not included. Only four of the eight non-typable isolates (of serotypes 23B, 28A and 29) were recovered from normally sterile sites. Therefore, $111 /$ $115(96.5 \%)$ of the isolates obtained from a normally sterile fluid were typed accurately using this multiplex PCR approach.

Table 1. S. pneumoniae serotype determination using two different sequential PCR schemes formulated for the USA and for Latin America

\begin{tabular}{|c|c|c|c|c|c|c|}
\hline \multirow[t]{2}{*}{ Reaction } & \multicolumn{3}{|c|}{ USA (Laval et al., 2006) } & \multicolumn{3}{|c|}{ Latin America (this study) } \\
\hline & Serotypes in each reaction ${ }^{*}$ & $n$ & Cumulative score $(\%)$ & Serotypes in each reaction ${ }^{*}$ & $n$ & Cumulative score (\%) \\
\hline PCR 1 & $3,6 \mathrm{~A} / 6 \mathrm{~B}, 19 \mathrm{~A}, 22 \mathrm{~F} /(22 \mathrm{~A})$ & 38 & $38(25.8)$ & $6 \mathrm{~A} / 6 \mathrm{~B}, 9 \mathrm{~V} /(9 \mathrm{~A}), 14,19 \mathrm{~F}, 23 \mathrm{~F}$ & 93 & $93(63.3)$ \\
\hline PCR 2 & $4,9 \mathrm{~V} /(9 \mathrm{~A}), 12 \mathrm{~F} /(12 \mathrm{~A}), 14$ & 52 & $90(61.2)$ & $1,4,5,18 \mathrm{C} /(18 \mathrm{~A}, 18 \mathrm{~B}, 18 \mathrm{~F}), 19 \mathrm{~A}$ & 25 & $118(80.3)$ \\
\hline PCR 3 & $\begin{array}{l}7 \mathrm{~F} /(7 \mathrm{~A}), 11 \mathrm{~A} /(11 \mathrm{D}), 23 \mathrm{~F}, 33 \mathrm{~F} / \\
(33 \mathrm{~A}, 37)\end{array}$ & 10 & $100(68.0)$ & $\begin{array}{l}3,7 \mathrm{~F} /(7 \mathrm{~A}), 9 \mathrm{~N} / 9 \mathrm{~L}, 10 \mathrm{~A}, 11 \mathrm{~A} / \\
(11 \mathrm{D})\end{array}$ & 13 & $131(89.1)$ \\
\hline PCR 4 & $\begin{array}{l}16 \mathrm{~F}, 18 \mathrm{C} /(18 \mathrm{~A}, 18 \mathrm{~B}, 18 \mathrm{~F}), 19 \mathrm{~F}, \\
35 \mathrm{~B}\end{array}$ & 20 & $120(81.6)$ & $\begin{array}{l}7 \mathrm{C} /(7 \mathrm{~B}, 40), 12 \mathrm{~F} /(12 \mathrm{~A}), 15 \mathrm{~B} / \\
15 \mathrm{C}, 17 \mathrm{~F}, 38\end{array}$ & 2 & $133(90.1)$ \\
\hline PCR 5 & $8,15 \mathrm{~B} / 15 \mathrm{C}, 31,38 /(25 \mathrm{~F})$ & 3 & $123(83.7)$ & $8,20,22 \mathrm{~F} /(22 \mathrm{~A}), 31,34$ & 4 & $137(93.2)$ \\
\hline PCR 6 & $1,10 \mathrm{~A}, 34,35 \mathrm{~F} /(47)$ & 9 & $132(89.8)$ & $\begin{array}{l}15 \mathrm{~A}, 16 \mathrm{~F}, 33 \mathrm{~F} /(33 \mathrm{~A}, 37), 35 \mathrm{~F} / \\
(47), 35 \mathrm{~B}\end{array}$ & 2 & $139(94.6)$ \\
\hline PCR 7 & $7 \mathrm{C} /(7 \mathrm{~B}, 40), 15 \mathrm{~A}, 17 \mathrm{~F}, 20$ & 1 & $133(90.5)$ & No reaction & & \\
\hline
\end{tabular}

${ }^{\star}$ Common serotype combinations are indicated by a slash mark. Rare serotypes are in parentheses. 

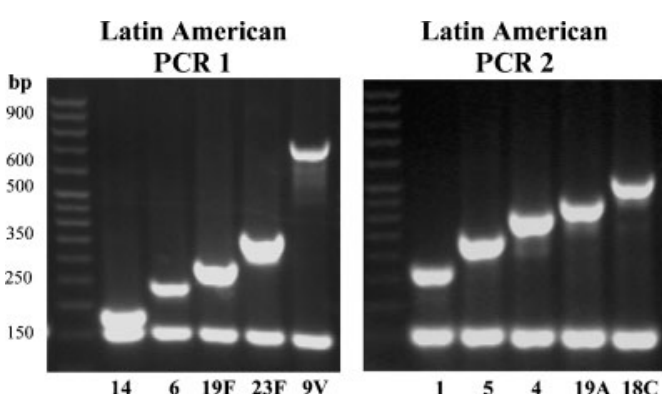

Latin American PCR 4

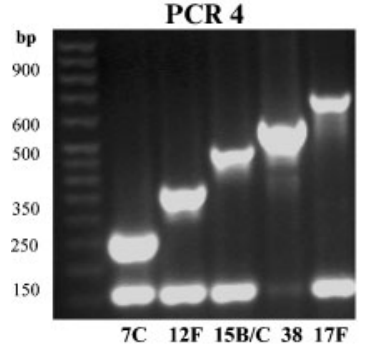

Latin American PCR 5

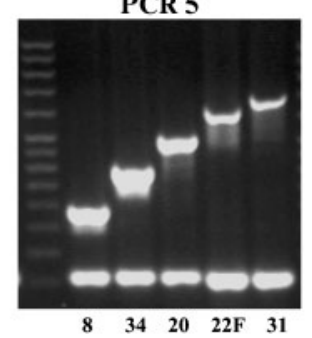

Latin American PCR 3

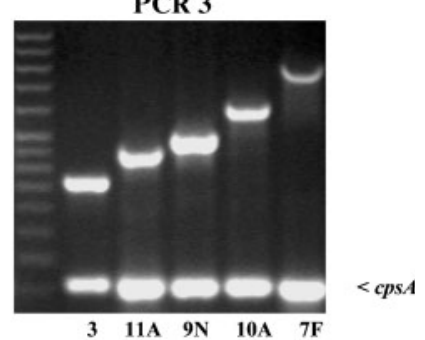

Latin American PCR 6

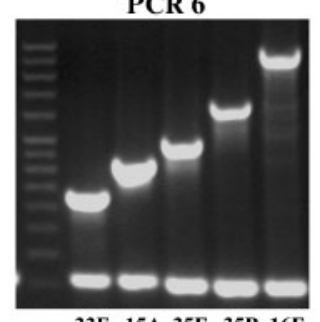

33F 15A 35F 35B 16F
Fig. 1. Latin America multiplex PCRs $1-6$ for the determination of $S$. pneumoniae serotypes.
Serotypes 4, 12F, 15A, 17F, 20, 22F, 33F, 35B, 35F and 38 were included in the scheme, but were not found among these isolates. The ability to detect these serotypes could potentially become more important in the future for postvaccine surveillance. For example, type $22 \mathrm{~F}$ is among the most common serotypes from invasive pneumococci in the USA in the post-PCV7 period (Whitney et al., 2006).

In summary, the multiplex PCR approach was successfully adapted to target serotypes most prevalent in Latin America and to identify serotypes from more than $90 \%$ of the isolates tested. This scheme can be used as an alternative to costly conventional serotyping in Latin American developing countries, allowing meaningful serotype surveillance by laboratories equipped only with basic PCR capability. The ability to determine prevalent pneumococcal capsular serotypes is currently important for the introduction and post-vaccine evaluation of new pneumococcal conjugate vaccines.

\section{ACKNOWLEDGEMENTS}

This study was supported in part by Conselho Nacional de Desenvolvimento Científico e Tecnológico (CNPq), Fundação de Amparo à Pesquisa do Estado do Rio de Janeiro (FAPERJ) and Ministério da Ciência e Tecnologia (MCT/PRONEX), Brazil.

\section{REFERENCES}

Arbique, J. C., Poyart, C., Trieu-Cuot, P., Quesne, G., Carvalho, M. G. S., Steigerwalt, A. G., Morey, R. E., Jackson, D., Davidson, R. J. \& Facklam, R. R. (2004). Accuracy of phenotypic and genotypic testing for identification of Streptococcus pneumoniae and description of Streptococcus pseudopneumoniae sp. nov. J Clin Microbiol 42, 4686-4696.
Brito, D. A., Ramirez, M. \& de Lencastre, H. (2003). Serotyping Streptococcus pneumoniae by multiplex PCR. J Clin Microbiol 41, 2378-2384.

Di Fabio, J. L., Castañeda, E., Agudelo, C. I., De la Hoz, F., Hortal, M., Camou, T., Echaniz-Avilés, G., Noemi, M., Barajas, C. \& other authors (2001). Evolution of Streptococcus pneumoniae serotypes and penicillin susceptibility in Latin America, Sireva-Vigía Group, 1993 to 1999. The PAHO Sireva-Vigía Study Group. Pediatr Infect Dis J 20, 959-967.

Garcia, S., Levine, O. S., Cherian, T., Gabastou, J. M., Andrus, J. \& Working Group Members (2006). Pneumococcal disease and vaccination in the Americas: an agenda for accelerated vaccine introduction. Rev Panam Salud Publica 19, 340-348.

Ghaffar, F., Barton, T., Lozano, J., Muniz, L. S., Hicks, P., Gan, V., Ahmad, N. \& McCraken, G. H., Jr (2004). Effect of the 7-valent pneumococcal conjugate vaccine on nasopharyngeal colonization by Streptococcus pneumoniae in the first 2 years of life. Clin Infect Dis 39, 930-938.

Hausdorff, W. P., Bryant, J., Paradiso, P. R. \& Siber, G. R. (2000). Which pneumococcal serogroups cause the most invasive disease: implications for conjugate vaccine formulation and use, part I. Clin Infect Dis 30, 100-121.

Kyaw, M. H., Lynfield, R., Schaffner, W., Craig, A. S., Hadler, J., Reingold, A., Thomas, A. R., Harrison, L. H., Bennett, N. M. \& other authors (2006). Effect of introduction of the pneumococcal conjugate vaccine on drug-resistant Streptococcus pneumoniae. N Engl J Med 354, 1455-1463.

Laval, C. B., de Andrade, A. L., Pimenta, F. C., de Andrade, J. G., de Oliveira, R. M., Silva, S. A., de Lima, E. C., Fabio, J. L., Casagrande, S. T. \& Brandileone, M. C. (2006). Serotypes of carriage and invasive isolates of Streptococcus pneumoniae in Brazilian children in the era of pneumococcal vaccines. Clin Microbiol Infect 12, 50-55.

Morais, L., Carvalho, Mda. G., Roca, A., Flannery, B., Mandomando, I., Soriano-Gabarró, M., Sigauque, B., Alonso, P. \& Beall, B. (2007). Sequential multiplex PCR for identifying pneumococcal capsular serotypes from south-Saharan African clinical isolates. $J$ Med Microbiol 56, 1181-1184. 
Pai, R., Gertz, R. E. \& Beall, B. (2006). Sequential multiplex PCR approach for determining capsular serotypes of Streptococcus pneumoniae isolates. J Clin Microbiol 44, 124-131.

Park, I. H., Pritchard, D. G., Cartee, R., Brandao, A., Brandileone, M. C. \& Nahm, M. H. (2007). Discovery of a new capsular serotype (6C) within serogroup 6 of Streptococcus pneumoniae. J Clin Microbiol 45, $1225-1233$.

Ray, G. T., Whitney, C. G., Fireman, B. H., Ciuryla, V. \& Black, S. B. (2006). Cost-effectiveness of pneumococcal conjugate vaccine: evidence from the first 5 years of use in the United States incorporating herd effects. Pediatr Infect Dis J 25, 494-501.

Robinson, K. A., Baughman, W., Rothrock, G., Barrett, N. L., Pass, M., Lexau, C., Lamaske, B., Stefonek, K., Barnes, B. \& other authors (2001). Epidemiology of invasive Streptococcus pneumoniae infection in the United States 1995-1998. Active Bacterial Core Surveillance (ABCs)/Emerging Infections Program Network. JAMA 285, 1729-1735.

Whitney, C. G., Farley, M. M., Hadler, J., Harrison, L. H., Bennett, N. M., Lynfield, R., Reingold, A., Cieslak, P. R., Pilishvili, T. \& other authors (2003). Decline in invasive pneumococcal disease after the introduction of protein-polysaccharide conjugate vaccine. Active Bacterial Core Surveillance (ABCs)/Emerging Infections Program Network. N Engl J Med 348, 1737-1746.

Whitney, C. G., Pilishivili, T., Farley, M. M., Schaffner, W., Craig, A. S., Lynfield, R., Nyquist, A. C., Gershman, K. A., Vazquez, M. \& other authors (2006). Effectiveness of seven-valent pneumococcal conjugate vaccine against invasive pneumococcal disease: a matched casecontrol study. Lancet 368, 1495-1502. 